\title{
IMPLEMENTASI KEBIJAKAN PENGEMBANGAN KABUPATEN/KOTA LAYAK ANAK DI PROVINSI KALIMANTAN TENGAH
}

\section{Implementation of Policy of District/City Development Worthy Of Children In Central Kalimantan Province}

\section{Riban Satia* \\ Triwik Puji Rahayu}

Universitas Muhammadiyah Palangkaraya, Palangka Raya,

Central Kalimantan, Indonesia

email:

dr.ribansatia@gmail.com

Kata Kunci:

Implementasi

Kebijakan

Pengembangan

Keywords:

Implementation

Policy

Development

\section{Accepted}

January 2018

Published

April 2018

\begin{abstract}
Abstrak
Tujuan penelitian ini adalah untuk mengetahui implementasi kebijakan Pengembangan Kabupaten/Kota Layak Anak (KLA) di Provinsi Kalimantan Tengah. Metode yang digunakan adalah kualitatif deskriptif. Teknik pengumpulan data menggunakan wawancara, observasi dan dokumentasi. Analisis data yang digunakan adalah model interaktif dari Miles \& Huberman dengan reduksi data, penyajian data, dan penarikan kesimpulan.

Hasil penelitian ini menunjukan bahwa kebijakan Pengembangan Kabupaten/Kota Layak Anak (KLA) sudah diimplementasikan di Provinsi Kalimantan Tengah, meski belum optimal karena kurang efektifnya komunikasi yang dilakukan kepada masyarakat. Hal lain yang menghambat kebijakan Pengembangan Kabupaten/Kota Layak Anak yaitu karena terbatasnya sumber daya anggaran, sehingga proses implementasi kebijakan Pengembangan Kabupaten/Kota Layak Anak Di Provinsi Kalimantan Tengah menjadi terhambat. Saran yang dapat disampaikan yaitu kepada Dinas Pemberdayaan Perempuan, Perlindungan Anak, Pengendalian Penduduk dan Keluarga Berencana (P3A-PPKB) besama dengan Dinas Pengendalian Penduduk dan Keluarga Berencana, Pemberdayaan Perempuan, Perlindungan Anak Tingkat Kabupaten/Kota untuk melakukan komunikasi yang lebih aktif dan berkelanjutan kepada masyarakat melalui pemasangan spanduk, banner, dan poster kreatif atau melalui media periklanan lainnya untuk meningkatkan pemahaman dan kepedulian masyarakat sehingga peran aktif masyarakat dalam proses implementasi kebijakan Pengembangan Kabupaten/Kota Layak Anak dapat meningkat. Melakukan pendekatan kepada pihak swasta agar dapat mengalokasikan anggaran Corporate Social Responsibility mereka untuk mendukung proses implementasi kebijakan Pengembangan Kabupaten/Kota Layak Anak Di Provinsi Kalimantan Tengah.
\end{abstract}

\begin{abstract}
The purpose of this research is to determine the implementation of the district/city Worthy Development policy (KLA) in central Kalimantan province. The method used is qualitative descriptive. Data collection techniques using interviews, observations and documentation. The data analysis used is the interactive model of Miles \& Huberman with data reduction, data presentation, and conclusion withdrawal.

The results of this research show that the policy of district development/city worthy of children (KLA) has been implemented in central Kalimantan province, although not optimal because of the lack of effective communication done to the public. Another thing that hinders the policy of district/city development worthy of children is because of the limited budget resources so that the implementation of the policy of District/city development worthy of children in central Kalimantan province becomes hampered. The advice that can be conveyed is to the Women Empowerment Department, Child protection, population control and family planning (P3A-PPKB) with the Office of Population Control and family planning, women empowerment, protection District level children to conduct more active and sustainable communication to the public through the installation of banners, banners, and creative posters or through other advertising media to improve the Community's understanding and awareness So that the active role of the community in the process of implementing district/city worthy development policy can increase. Approach the private sector to allocate the budget of their Corporate Social Responsibility to support the implementation of the district/city proper development policy in Central Kalimantan province.
\end{abstract}




\section{PENDAHULUAN}

Kebijakan Pengembangan Kabupaten/Kota Layak Anak merupakan wujud upaya pemerintah dalam mentransformasikan hak anak pada proses pembangunan, sehingga dalam setiap perencanaan pembangunan selalu mempertimbangkan hak anak, dengan terbitnya Kebijakan Pengembangan Kabupaten/Kota Layak Anak diharapkan akan memberi perubahan dan pengaruh besar terhadap pemenuhan hak anak di Indonesia sehingga seluruh kawasan di Indonesia benar-benar menjadi tempat yang layak bagi anak.

Selain itu, Menteri Pemberdayaan Perempuan dan Perlindungan Anak juga menerbitkan sebuah peraturan yang dikhususkan bagi Pemerintah Provinsi dalam mengembangkan Kabupaten/Kota Layak Anak yaitu Peraturan Menteri Negara Pemberdayaan Perempuan dan Perlindungan Anak Nomor I4 Tahun 2010 Tentang Pedoman Pengembangan Kabupaten/Kota Layak Anak Tingkat Provinsi. Pada tahun 2013, Gubernur Kalimantan Tengah mengeluarkan sebuah Peraturan Gubernur Nomor 69 Tahun 2013 Tentang Pedoman Pengarusutamaan Hak Anak Dalam Pengembangan Kabupaten/Kota Layak Anak. Meski telah memiliki dasar hukum berupa Peraturan Gubernur, tidak serta-merta membuat permasalahan mengenai pemenuhan hak anak selesai, masih terdapat permasalahan mengenai hak anak di Provinsi Kalimantan Tengah yang terlanggar, seperti masih ada anak yang lahir tapi tidak dicatatkan pada akta kelahiran.

Fasilitas umum penunjang pertumbuhan fisik dan psikis anak kiranya perlu mendapat perhatian, taman terbuka yang memiliki fasilitas bermain standar dan merangsang pertumbuhan anak masih dapat dihitung dengan jari,sebab taman terbuka tidak hanya sebagai area bermain untuk melatih perkembangan fisik saja namun juga sebagai sarana untuk membangun atau mendekatkan hubungan emosional baik anak dengan orang tua maupun dengan teman seusianya mengingat kecerdasan emosional sama pentingnya dengan kecerdasan inteligensia.

Saat ini masih sangat jarang tempat umum yang menyediakan ruangan khusus bagi ibu yang hendak memberikan air susu ibu (ASI) eksklusif untuk bayinya atau ruang laktasi sehingga terkadang membuat para ibu kesulitan. Begitu pula dengan ruangan khusus merokok juga tidak selalu ada ditempat umum, akibatnya tidak jarang anak-anak ikut terkena paparan asap rokok, selain karena paru-paru anak tidak sekuat orang dewasa, terdapat zat berbahaya pada rokok dapat menjadi ancaman bagi anak-anak.

Permasalahan lainnya yaitu adanya fenomena pelajar tingkat SMP yang berangkat maupun pulang sekolahmenggunakan kendaraan bermotor. Hal tersebut bukannya tanpa alasan, sebab utama adanya fenomena tersebut ialah karena belum adanya transportasi dari dan menuju sekolah yang aman dan ramah bagi anak seperti bus sekolah, sementara jarak dari rumah menuju sekolah bagi sebagian pelajar SMP relatif jauh jika tempuh dengan berjalan kaki atau bersepeda. Dengan alasan tersebut para orang tua terlebih bagi kedua orang tua yang memiliki kesibukan bekerja, terpaksa memberikan izin bagi anaknya untuk mengendarai sepeda motor.

Mengenai betapa kompleksnya hak anak yang terlanggar dan belum ada penelitian yang mengkaji tentang Kebijakan Pengembangan Kabupaten/Kota Layak Anak di Provinsi Kalimantan Tengah padahal usia anak merupakan waktu yang tepat dalam mempersiapkan generasi penerus bangsa yang berkualitas, membuat penulis tertarik dan merasa bahwa permasalahan mengenai hal tersebut layak untuk dijadikan sebuah penelitian.

\section{METODOLOGI}

Dalam hal ini peneliti menggunakan pendekatan kualitatif, Karena peneliti ingin mengetahui gambaran mendalam mengenai apa yang tersembunyi pada fenomena yang sulit untuk diketahui dan dipahami, dan 
untuk memperoleh informasi yang faktual dan akurat serta pemecahan masalah pada saat penelitian dilakukan.

Sedangkan permasalahan yang diteliti sangat kompleks, dinamis, dan penuh makna sehingga sangat cocok jika menggunakan metode penelitian kualitatif yang diharapkan mampu memberikan penjelasan rinci tentang fenomena tersebut dengan menggunakan instrumen penelitian yaitu peneliti sendiri. Namun Dalam penelitian yang menjadi informan adalah para aktor yang memiliki kapasitas, tanggungjawab, informasi, atapun pengetahuan terhadap jalannya implementasi Kebijakan Pengembangan Kabupaten/ Kota Layak Anak di Provinsi Kalimantan Tengah.

\section{HASIL DAN PEMBAHASAN}

Kebijakan Kabupaten/Kota Layak anak berawal dari adanya reaksi para aktivis dunia yang meminta perhatian publik akan nasib dan penderitaan anak-anak yang menjadi korban perang akibat perang dunia I. Disadari bahwa dimasa depan permasalahan mengenai hak-hak anak akan semakin kompleks, untuk itu kemudian dilakukan penandatanganan konvensi hak anak (Covention of the Right of the Child) pada tahun 1989 oleh berbagai Negara di dunia, konvensi hak anak sendiri merupakan sebuah perjanjian yang bersifat mengikat baik secara yuridis maupun politis antar berbagai negara di dunia yang mengatur hal-hal mengenai hak anak.

Dilanjutkan dengan komitmen bersama oleh para pemimpin dunia pada tahun 2002 dengan menegaskan kembali komitmen dan kewajiban untuk berupaya memenuhi hak-hak anak melalui dokumen yang diberi nama A World Fit For Children (sebuah dunia yang Layak untuk anak) untuk menciptakan dunia yang layak bagi anak, yaitu dunia dimana semua anak mendapatkan awal kehidupan yang sebaik mungkin. Konvensi hak anak tersebut menjadi "payung" atau acuan bagi munculnya komitmen internasional untuk pemenuhan hak anak salah satunya World Fit For Children.

Di Indonesia pada tahun 2002, Rancangan UndangUndang (RUU) tentang Perlindungan Anak disetujui bersama antara Dewan Perwakilan Rakyat (DPR) dan Pemerintah disahkan sebagai Undang-Undang Negara Republik Indonesia Nomor 23 Tahun 2002 Tentang Perlindungan Anak yang kemudian digantikan oleh Undang-Undang yang baru yaitu Undang-Undang Negara Republik Indonesia Nomor 35 Tahun 2014 Tentang Perlindungan Anak. Undang-Undang Perlindungan Anak inilah yang

merupakan salah satu bagian untuk mengoperasionalkan konvensi hak anak karena Undang-Undang Perlindungan Anak tersebut memberikan instrumen yang sangat kuat untuk mengimplementasikan konvensi hak anak di Indonesia. Sedangkan kaitan Undang-Undang Perlindungan Anak dengan Kebijakan Pengembangan Kabupaten/Kota Layak Anak sendiri yaitu Undang-Undang Perlindungan Anak merupakan salah satu perundangan nasional yang menjadi landasan kebijakan Kabupaten/Kota Layak Anak, dimana Kabupaten/Kota Layak Anak bertujuan untuk melakukan berbagai upaya pemenuhan hak anak secara holistik, integratif dan berkelajutan yang tercantum dalam Undang-Undang Perlindungan Anak sehingga pada tahun 2030 Indonesia Layak Anak dapat terwujud.

Pada pembahasan ini peneliti membahas hasil penelitian mengenai kebijakan Pengembangan Kabupaten/Kota Layak Anak Di Provinsi Kalimantan Tengah, yang mana pendekatannya bersifat top down dan menggunakan teori yang dirumuskan oleh George C. Edward III. Terdapat empat indikator menurut George C. Edward NIII yang dapat mempengaruhi implementasi kebijakan yaitu:

I. Komunikasi

Hasil penelitian terkait komunikasi dalam implementasi kebijakan Pengembangan Kabupaten/ 
Kota Layak Anak diketahui bahwa Dinas P3APPKB Provinsi Kalimantan Tengah bersama dengan SKPD lainnya yang tergabung dalam Tim Gugus Tugas Kabupaten/Kota Layak Anak Provinsi Kalimantan Tengah telah beberapa kali mengadakan rapat terkait kebijakan tersebut.

Dari beberapa hasil rapat yang dicapai, salah satunya adalah keputusan bahwa masingmasing SKPD diminta membuat rencana aksi yangN mampu mendukung pemenuhan hak anak di Provinsi Kalimantan Tengah. Pemerintah Provinsi Kalimantan Tengah dalam hal ini adalah Dinas P3A-PPKB Provinsi Kalimantan Tengah juga melaksanakan kegiatan Sosialisasi/ Advokasi Pengembangan Pengarusutamaan Hak Anak Di Kabupaten/Kota se Kalimantan Tengah, sasarannya yaitu kepada Pemerintah Kabupaten/Kota terutama Dinas Pemberdayaan Perempuan dan Perlindungan Anak di tingkat Kabupaten/ Kota sehingga Pemerintah Kabupaten/Kota dapat membuat program maupun kegiatan terkait Kabupaten/Kota Layak Anak. Hal ini penting dilakukan agar kejelasan informasi kebijakan dapat diterima dengan baik sehingga Pemerintah Kabupaten/Kota dapat mengetahui maksud, tujuan dan sasaran kebijakan itu.

Selain itu, belum ada upaya lain dari Pemerintah Provinsi Kalimantan Tengah dan Pemerintah Kabupaten/Kota dalam menyampaikan informasi seperti melalui surat kabar, radio, poster, sanduk atau baliho. Padahal penyampaian informasi yang dianggap paling efektif diantaranya menggunakan media tersebut karena pertimbangan bahwa media-media tersebut dekat dengan masyarakat, ditunjang dengan mobilitas masyarakat Provinsi Kalimantan Tengah yang sudah sangat tinggi saat ini, sehingga jika informasi disampaikan melalui spanduk atau baliho maka kebijakan tersebut akan cepat dipahami dan diterima masyarakat, sedangkan penyampaian informasi melalui radio dapat memperluas jangkauan hingga kepada masyarakat pedesaan.

2. Sumber Daya

Selanjutnya dari segi kualitas sumber daya manusia, sebagian besar pelaksana kebijakan telah memahami hal yang melatarbelakangi adanya kebijakan Pengembangan Kabupaten/Kota Layak Anak, serta maksud dan tujuan adanya kebijakan itu. Hal yang terpenting yaitu pelaksana kebijakan telah memahami apa yang menjadi tugasnya dalam kebijakan Pengembangan Kabupaten/Kota Layak Anak di Provinsi Kalimantan Tengah, diantaranya mendorong Pemerintah Kabupaten/Kota agar menjadikan daerahnya sebagai Kabupaten/Kota Layak anak dengan melakukan sosialisasi/advokasi pada Kabupaten/Kota se Kalimantan Tengah dan Pemerintah Kabupaten/Kota memiliki kewajiban untuk melakukan sosialisasi kepada masyaraka

Berbeda halnya dengan sumber daya manusia, pada sumber daya non manusia, peneliti menemukan beberapa adanya masalah. Seperti yang telah peneliti uraikan dalam hasil penelian, diketahui bahwa Sosialisasi/Advokasi Pengembangan Pengarusutamaan Hak Anak Di Kabupaten /Kota se Kalimantan Tengah hanya dilaksanakan dua hingga tiga kali dalam satu tahun, padahal untuk menyebarluaskan informasi kepada masrayakat tidak cukup hanya dengan satu kali sosialisasi saja.

3. Disposisi/Kecenderungan

Disposisi atau kecendererungan merupakan sejauh mana keinginan dan komitmen untuk melaksanakan kebijakan yang ditetapkan. Pengetahuan, pemahaman dan komitmen terhadap kebijakan adalah penting bagi pelaksana kebijakan, apabila telah mengetahui dan memahami tujuan kebijakan makan pelaksana kebijakan akan berupaya menentukan langkah yang harus diambil agar kebijakan dapat berjalan sebagaimana mestinya. Sedangkan komitmen yang tinggi akan membuat pelaksana kebijakan selalu antusias 
terhadap tugas, fungsi, dan tanggungjawab sesuai dengan yang telah ditetapkan

4. Struktur Birokrasi

Berdasarkan hasil penelitian, dimensi fragmentasi ditunjukan melalui struktur organisasi pada Dinas P3A-PPKB Provinsi Kalimantan Tengah yang sangat jelas menggambarkan adanya penyebaran tanggungjawab pada bidangbidang yang ada. Sedangkan bidang yang melaksanakan kebijakan Pengembangan Kabupaten/Kota Layak Anak yaitu pada Bidang Perlindungan dan Pemenuhan Hak Anak sehingga pelaksana kebijakan bekerja sesuaidengan tugas dan tanggungjawabnya. Pada tingkat Kabupaten/Kota, Dinas yang secara teknis ditunjuk sebagai pelaksana kebijakan Pengembangan Kabupaten/ Kota Layak Anak adalah Dinas Pengendalian Penduduk dan Keluarga Berencana, Pemberdayaan Perempuan dan Perlindungan Anak, di Bidang Perlindungan dan Tumbuh Kembang Anak.

\section{KESIMPULAN}

I. Dinas P3A-PPKB Provinsi Kalimantan Tengah sebagai leading sector bersama dengan Satuan Kerja Perangkat Daerah (SKPD) lainnya yang tergabung dalam Tim Gugus Tugas Kabupaten/Kota Layak Anak Provinsi Kalimantan Tengah telah menjalin komunikasi dengan baik untuk memperlancar proses implementasi kebijakan Pengembangan Kabupaten/Kota Layak Anak Di Provinsi Kalimantan Tengah. Hal itu dapat dilihat dari adanya pertemuan rapat koordinasi mengenai kebijakan tersebut salah satunya terkait dengan rencana aksi yang dibuat SKPD yang dapat mendukung upaya-upaya pemenuhan hak anak di Provinsi Kalimantan Tengah.

2. Namun Pada proses implementasi kebijakan Pengembangan Kabupaten/Kota Layak Anak Di Provinsi Kalimantan Tengah menunjukan bahwa ada dua garis besar sumber daya yang dimaksud adalah sumber daya manusia dan sumber daya non manusia.

3. Sedangkan dari sisi pelaksana kebijakan mendukung sepenuhnya kebijakan tersebut. Sikap pelaksana kebijakan baik dari Dinas P3A-PPKB Provinsi Kalimantan Tengah maupun SKPD dalam Tim Gugus Tugas Kabupaten/Kota Layak Anak dinilai sudah baik, hal itu dapat terlihat dari meskipun adanya beberapa kekurangan seperti terbatasnya anggaran namun pelaksana kebijakan tetap berupayaB menjalankan kebijakan tersebut dengan sebaik mungkin dan tidak menjadikan hambatan itu sebagai suatu penghalang.

4. Strukur birokrasi mencakup dua dimensi yaitu fragmentasi dan Standar Operasional Prosedur (SOP). Dimensi fragmentasi ditunjukan melalui struktur organisasi pada Dinas P3A-PPKB Provinsi Kalimantan Tengah yang sangat jelas menggambarkan adanya penyebaran tanggungjawab, bidang yang melaksanakan kebijakan Pengembangan Kabupaten/Kota Layak Anak yaitu pada Bidang Perlindungan dan Pemenuhan Hak Anak. Pada tingkat Kabupaten/Kota, Dinas yang secara teknis ditunjuk sebagai pelaksana kebijakan Pengembangan Kabupaten /Kota Layak Anak adalah Dinas Pengendalian Penduduk dan Keluarga Berencana, Pemberdayaan Perempuan dan Perlindungan Anak, di Bidang Perlindungan dan Tumbuh Kembang Anak.

\section{REFERENSI}

Agus, Erwan Purwanto dan Dyah Ratih Sulistyastuti. 2012. Implementasi Kebijakan Publik: Konsep dan Aplikasinya Di Indonesia. Yogyakarta: Gava Media.

Agustino, Leo. 2014. Dasar-Dasar Kebijakan Publik. Bandung: Alfabeta. 
Basrowi \& Suwandi. 2008. Memahami Penelitian Kualitatif. Jakarta: PT Rineka Cipta.

Badan Pusat Statistik, 2016. Provinsi Kalimantan Tengah Dalam Angka. 2016. Kalimantan Tengah: BPS Provinsi Kalimantan Tengah.

Emzir. 2012. Metodologi Penelitian Kualitatif: Analisis Data. Jakarta: PT RajaGrafindo Persada.

Gunawan, Imam. 20I4. Metode Penelitian Kualitatif Teori \& Praktik. Jakarta: Bumi Aksara.

Kalimantan Tengah, 20I3. Keputusan Gubernur Kalimantan Tengah Nomor 188.44/721/2013 Tentang Pembentukan Gugus Tugas Kabupaten IKota Layak Anak Provinsi Kalimantan Tengah Tahun 2013-2017. Palangkaraya: Sekretariat Daerah Kalimantan Tengah.

Kalimantan Tengah, 20I3. Peraturan Gubernur Nomor 69 Tahun 2013 Tentang Pedoman Pengarusutamaan Hak Anak Dalam Pengembangan Kabupaten/Kota Layak Anak Tingkat Provinsi Kalimantan Tengah. Palangkaraya: Sekretariat Daerah Kalimantan Tengah.

Mantra, Ida Bagoes. 2016. Filsafat Penelitian dan Metode Penelitian Sosial. Yogyakarta: Pustaka Belajar.

Nugroho, Riant. 20II. Public Policy. Jakarta: PT Elex Media Komputindo

Nugroho, Riant. 2013. Metode Penelitian Kebijakan. Yogyakarta: Pustaka Belajar.

Subarsono. 20I5. Analisis Kebijakan Publik. Yogyakarta: Pustaka Belajar.

Wahab, Solihin Abdul. 2015. Analisis Kebijaksanaan dan Formulasi Ke Implementasi Kebijaksanaan Negara. Jakarta: Bumi Aksara.

Widodo, Joko. 2016. Analisis Kebijakan Publik. Malang: Media Nusantara Creative. 